\title{
Glucagon-Like Peptide-I Receptor Signaling in the Lateral Parabrachial Nucleus Contributes to the Control of Food Intake and Motivation to Feed
}

\author{
Amber L Alhadeff*,', John-Paul Baird ${ }^{2}$, Jennifer C Swick², Matthew R Hayes ${ }^{3}$ and Harvey J Grill*, \\ 'Department of Psychology, University of Pennsylvania, Philadelphia, PA, USA; ${ }^{2}$ Program in Neuroscience, Amherst College, Amherst, MA, USA; \\ ${ }^{3}$ Department of Psychiatry, University of Pennsylvania, Philadelphia, PA, USA
}

\begin{abstract}
Central glucagon-like peptide-I receptor (GLP-IR) activation reduces food intake and the motivation to work for food, but the neurons and circuits mediating these effects are not fully understood. Although lateral parabrachial nucleus (IPBN) neurons are implicated in the control of food intake and reward, the specific role of GLP-IR-expressing IPBN neurons is unexplored. Here, neuroanatomical tracing, immunohistochemical, and behavioral/pharmacological techniques are used to test the hypothesis that IPBN neurons contribute to the anorexic effect of central GLP-IR activation. Results indicate that GLP-I-producing neurons in the nucleus tractus solitarius project monosynaptically to the IPBN, providing a potential endogenous mechanism by which IPBN GLP-IR signaling may exert effects on food intake control. Pharmacological activation of GLP-IR in the IPBN reduced food intake, and conversely, antagonism of GLP-IR in the IPBN increased food intake. In addition, IPBN GLP-IR activation reduced the motivation to work for food under a progressive ratio schedule of reinforcement. Taken together, these data establish the IPBN as a novel site of action for GLP-IR-mediated control of food intake and reward.

Neuropsychopharmacology (2014) 39, 2233-2243; doi:I0.1038/npp.2014.74; published online I6 April 2014
\end{abstract}

\section{INTRODUCTION}

Glucagon-like peptide-1 (GLP-1) is a neuropeptide involved in the control of food intake and glycemia that is primarily released from preproglucagon-expressing enteroendocrine L cells in the small intestine and in nucleus tractus solitarius (NTS) neurons of the caudal brainstem (Holst, 2007). Given the increasing attention paid to: (1) the GLP-1 system as a target for obesity treatment (Astrup et al, 2009), (2) the role of central nervous system (CNS) GLP-1 receptor (GLP-1R) signaling in mediating long-acting GLP-1R agonist effects (Hayes et al, 2010; Kanoski et al, 2011a), and (3) the anatomically distributed nature of the control of energy balance (Grill and Hayes, 2012), it is important to expand the analysis of GLP1-R-expressing nuclei to identify the neurons and circuits that contribute to its energy balance effects. Although GLP-1Rs are widely expressed throughout the brain, studies have focused mainly on GLP-1R signaling in the hypothalamus (McMahon and Wellman, 1998; Schick et al, 2003) and NTS (Hayes et al, 2009; Hayes et al, 2011).

\footnotetext{
*Correspondence: AL Alhadeff, Department of Psychology, University of Pennsylvania, 3720 Walnut Street D25, Philadelphia, PA 19104, USA, Tel: +6105338326, Fax: +215898730I, E-mail: amberla@sas.upenn.edu or Dr HJ Grill, Department of Psychology, University of Pennsylvania, 3720 Walnut Street D24, Philadelphia, PA 19104, USA,

E-mail: grill@psych.upenn.edu

Received 30 October 2013; revised 12 March 2014; accepted 13 March 2014; accepted article preview online 26 March 2014
}

Only recently have the functional contributions of GLP-1R-expressing nuclei in the ventral tegmental area (VTA) and the nucleus accumbens (NAc) to food intake and reward been addressed (Alhadeff et al, 2012; Dickson et al, 2012; Dossat et al, 2011; Mietlicki-Baase et al, 2013a). Here, we investigate the role of endogenous and exogenous GLP-1R signaling in the parabrachial nucleus (PBN) in the control of feeding and motivation to feed.

The pontine PBN is an important neural processing hub that receives input from and projects to neurons in a variety of brain nuclei considered key contributors to energy balance and reward control. Monosynaptic connections from the NTS (both the rostral and caudal divisions) conveying visceral afferent signals (including taste and gastrointestinally-derived satiation signals) are processed by PBN neurons (Blessing, 1997; Cho et al, 2002; Norgren, 1978). PBN neurons in turn project to various nuclei critical for the control of energy balance including but not limited to nuclei of the hypothalamus (Blessing, 1997; Norgren, 1976), amygdala (Blessing, 1997; Norgren, 1976), VTA (Miller et al, 2011), and NAc (Li et al, 2012). The lateral subnuclei of the PBN (lPBN), which receive visceral afferent information from the caudal NTS, also receive descending projections from several nuclei that are implicated in food intake control, including nuclei of the amygdala, bed nucleus of the stria terminalis, and the hypothalamus (Blessing, 1997; Zhang et al, 2011a). Previous studies have demonstrated that a variety of neurochemicals including 
endocannabinoids (DiPatrizio and Simansky, 2008), opioids (Chaijale et al, 2013; Wilson et al, 2003), $\gamma$-aminobutyric acid (GABA) (De Oliveira et al, 2011; Wu et al, 2009), glutamate (Wu et al, 2012), and melanocortin (Skibicka and Grill, 2009) act in the IPBN to alter food intake and/or reward processing, highlighting the relevance of additional focus on the $1 P B N$ as a hindbrain region relevant to the control of energy balance. Despite the presence of GLP-1R mRNA (Merchenthaler et al, 1999) and terminals of GLP-1immunopositive fibers (Rinaman, 2010) in the PBN, a direct analysis of 1PBN GLP-1R signaling in the control of feeding behavior remains unexplored.

The studies described here combine neuroanatomical tracing, immunohistochemical, and behavioral/pharmacological techniques to study the neural connections between NTS GLP-1-producing neurons and the 1PBN, as well as the effects of 1PBN GLP-1R signaling on feeding and motivation to work for food. Collectively, the results obtained indicate that GLP-1R signaling in the $1 P B N$ is physiologically relevant for the control of food intake and motivation to work for food, putatively through monosynaptic projections from NTS GLP-1-producing neurons.

\section{MATERIALS AND METHODS}

\section{Subjects and Drugs}

Adult male Sprague-Dawley rats (250-300 g upon arrival; Charles River Laboratories, Wilmington, MA) were individually housed in hanging metal cages on a $12 \mathrm{~h}$ light $/ 12 \mathrm{~h}$ dark cycle and had ad libitum access to standard pelleted chow (Purina Rodent Chow, 5001) and water except when otherwise noted. All procedures conformed to and received approval from the institutional standards of the University of Pennsylvania animal care and use committee.

The long-acting GLP-1R agonist exendin-4 (American Peptide, Sunnyvale, CA) and GLP-1R antagonist exendin(9-39) (Bachem Americas, Torrence, CA) were dissolved in artificial cerebrospinal fluid (aCSF). The monosynaptic retrograde tracer Fluorogold (Fluorochrome, LLC, Denver, $\mathrm{CO})$ was diluted to $2 \%$ in distilled water.

\section{Surgery}

Rats received intramuscular ketamine $(90 \mathrm{mg} / \mathrm{kg}$; Butler Animal Health Supply, Dublin, OH), xylazine $(2.7 \mathrm{mg} / \mathrm{kg}$; Anased, Shenandoah, IA) and acepromazine $(0.64 \mathrm{mg} / \mathrm{kg}$; Bitler Animal Health Supply) anesthesia and subcutaneous analgesia $(2.0 \mathrm{mg} / \mathrm{kg}$ Metacam; Boehringer Ingelheim Vetmedica, St Joseph, MO) for all surgeries.

Unilateral 26-gauge guide cannulae (Plastics One, Roanoke, VA) were stereotaxically implanted in the IPBN or the cerebral aqueduct according to the following coordinates. IPBN guide cannulae were positioned $\pm 2.0 \mathrm{~mm}$ lateral from midline, $0.6 \mathrm{~mm}$ anterior to lambda, and $5.7 \mathrm{~mm}$ ventral from skull surface using a $20^{\circ}$ angle (negative slope in anterior to posterior direction) with the injector aimed $2.0 \mathrm{~mm}$ below the end of the guide cannula. Cannula placements were histologically confirmed postmortem. A representative image of the injection site is depicted in Figure 1c. Animals with injection sites that were not within the IPBN were excluded from the analyses.
On this basis, two animals were excluded from Experiment 4, three animals were excluded from Experiment 5, and one animal was excluded from Experiment 8. Aqueduct guide cannulae were positioned anterior to the $\mathrm{PBN}, \pm 2.0 \mathrm{~mm}$ medial from midline, $8.2 \mathrm{~mm}$ caudal anterior from bregma, and $3.85 \mathrm{~mm}$ ventral from skull using a $20^{\circ}$ angle (negative slope in the lateral-to-medial direction). Cannula placements were functionally confirmed via measurement of the sympathoadrenal-mediated glycemic response to 5-thio-Dglucose $(210 \mu \mathrm{g} / 2 \mu \mathrm{l}$ in aCSF $)$ injected into the aqueduct as previously described (Ritter et al, 1981). A post-injection increase in blood glucose level of at least 100\% from baseline was necessary for subject inclusion.

\section{Experimental Procedures}

Experiment 1: IPBN fluorogold tracing and NTS GLP-1 immunohistochemistry. Using a protocol similar to the one previously established in our laboratory (Alhadeff et al, $2012)$, rats $(n=5)$ were lightly anesthetized and received a unilateral $300 \mathrm{nl}$ injection of $2 \%(\mathrm{w} / \mathrm{v})$ Fluorogold (FG; Fluorochrome, LLC) via an automated syringe pump (PHD Ultra; Harvard Apparatus, Holliston, MA) directed to the $1 \mathrm{PBN}$. Four days later, rats were deeply anesthetized and transcardially perfused with $0.1 \mathrm{M} \mathrm{pH} \mathrm{7.4} \mathrm{PBS} \mathrm{(Boston}$ Bioproducts, Ashland, MA), followed by $4 \%$ paraformaldehyde (PFA; Boston Bioproducts,). Brains were removed and postfixed in $4 \%$ PFA for $4 \mathrm{~h}$ and subsequently stored in $20 \%$ sucrose in $0.1 \mathrm{M}$ PBS at $4{ }^{\circ} \mathrm{C}$ overnight. Coronal sections $(30 \mu \mathrm{m})$ were cut from the caudal hindbrain using a cryostat (Leica 3050 S; Leica, Deerfield, IL) and collected serially in glass jars. Brain sections were stored at $4{ }^{\circ} \mathrm{C}$ overnight until the start of immunohistochemistry (IHC).

IHC for GLP-1 was conducted according to modified previous procedures (Alhadeff et al, 2012; Zhang et al, 2011b). Briefly, sections were treated consecutively with $1 \%$ $\mathrm{H}_{2} \mathrm{O}_{2}$ in precooled methanol, $0.3 \%$ glycine, and blocking solution (5\% normal donkey serum in $0.1 \mathrm{M}$ PBS with $2.5 \%$ Triton X), then incubated with the GLP-1 primary antibody (GLP-1-(7-37) antiserum; Bachem Americas, Torrance, CA) at a $1: 2000$ concentration in blocking solution for $18 \mathrm{~h}$ at room temperature. Sections were then washed and incubated with the secondary antibody (DyLight 549; Jackson ImmunoResearch Laboratories, West Grove, PA) at a 1:500 concentration in blocking solution for $2 \mathrm{~h}$. Detection of FG autofluorescence was observed under a special filter (C-FL UV-2A; Nikon Instruments, Melville, NY) on a fluorescence microscope (Nikon 80 i; Nikon Instruments, Melville, NY).

Brain sections were mounted on slides and coverslipped with Fluorogel (Electron Microscopy Sciences; Hatfield, PA). Using fluorescence microscopy (Nikon $80 \mathrm{i}$; NIS Elements $A R$ 3.0) at $\times 10$ and $\times 20$ magnification, neurons expressing FG and GLP-1 immunofluorescence were quantified from coronal sections ( $\geqslant 8$ sections per brain) of the caudal brainstem between $-14.8 \mathrm{~mm}$ and $-14.1 \mathrm{~mm}$ from bregma, according to the stereotaxic atlas of Paxinos and Watson (2005).

Experiment 2: parenchymal dose selection: evaluation of food intake effects of GLP-1R agonist and antagonist delivery to the cerebral aqueduct. To ensure that doses used in subsequent IPBN experiments were subthreshold for 

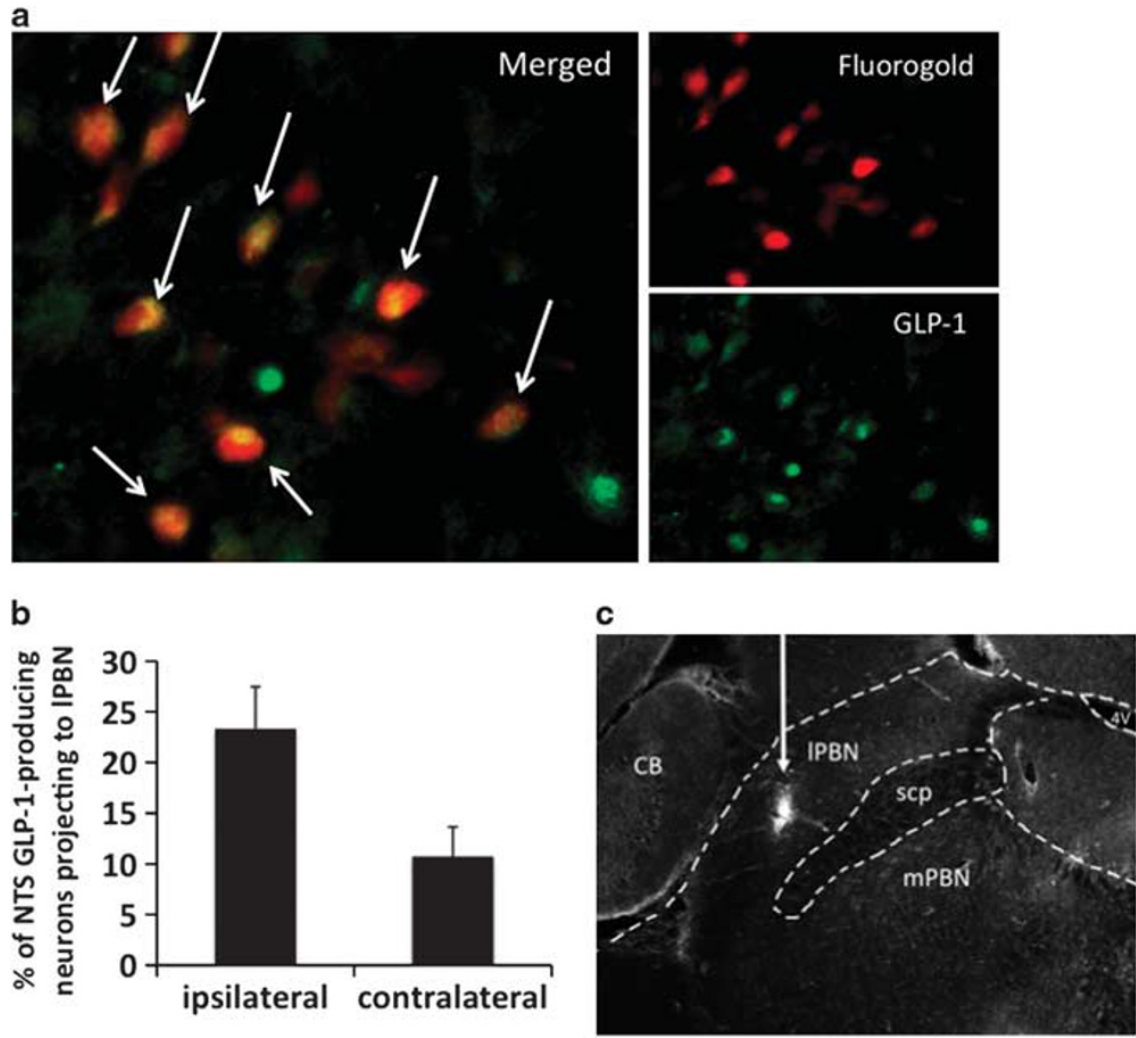

Figure I Colocalizion of caudal NTS GLP-I-producing neurons and IPBN-injected Fluorogold. (a) Representative $\times 20$ magnification image of a coronal NTS section; red immunofluorescence represents Fluorogold-expressing neurons and green immunofluorescence represents GLP-I-expressing neurons. (b) Quantification of neurons in the caudal NTS showed that $23.2 \pm 4.2 \%$ of ipsilateral NTS GLP-I neurons and $10.6 \pm 3.0 \%$ of contralateral NTS GLP-I neurons project monosynaptically to the IPBN (means \pm SEM). (c) Representative image of IPBN injection site (white arrow). CB, cerebellum; IPBN, lateral parabrachial nucleus; mPBN, medial parabrachial nucleus; scp, superior cerebellar peduncle; $4 \mathrm{~V}$, fourth ventricle.

effect when delivered into the cerebroventricular system, rats $(n=9)$ maintained ad libitum on high-fat diet (HFD; $45 \% \mathrm{kcal} /$ fat, Research Diets, New Brunswick, NJ) for 5 days and habituated to experimental procedures, received a $200 \mathrm{nl}$ unilateral injection of aCSF, exendin-4 (0.025 or $0.05 \mu \mathrm{g})$, or exendin-(9-39) (10 or $20 \mu \mathrm{g})$ in the aqueduct in a within-subjects, counterbalanced experimental design immediately before the onset of the dark cycle. The effects of aqueduct-delivered exendin- 4 and exendin-9 on HFD ( $v s$ chow) intake were examined given that the drug effects are more pronounced with HFD when delivered to some central nuclei (see the following experiments and Alhadeff et al, 2012). HFD intake was measured at $1,3,6$, and $24 \mathrm{~h}$ accounting for spillage. Body weight and water intake were measured $24 \mathrm{~h}$ post injection. At least $48 \mathrm{~h}$ elapsed in between drug injection conditions.

Experiment 3: effects of $l P B N$ GLP-1R activation on chow intake. Rats $(n=15)$ were housed in a custom- made, automated feedometer, which consists of hanging wire cages with a small access hole to a food cup resting on an electronic scale. The associated software (LabView) records the weight of the food cup every $10 \mathrm{~s}$. Following habituation to the cages and powdered standard chow for 5 days, rats received a $100 \mathrm{nl}$ unilateral injection of aCSF or exendin-4 $(0.025$ or $0.05 \mu \mathrm{g})$ in a within-subjects, counterbalanced experimental design immediately before the onset of the dark cycle. These exendin- 4 doses were determined to be subthreshold for a reduction in food intake when delivered to the aqueduct cannula positioned just rostral from the PBN (Experiment 2). Automated food measurements were made for the $24 \mathrm{~h}$ post injection; body weight and water intake were manually recorded $24 \mathrm{~h}$ post injection. At least $48 \mathrm{~h}$ elapsed in between drug injection conditions.

Experiment 4: pica effects of $l P B N$ GLP-1R activation. To determine whether reductions in feeding resulting from IPBN GLP-1R activation might be attributable to nausea/ malaise, pica (the ingestion of non-nutritive substances) was assessed as previously reported (Alhadeff et al, 2012; Kanoski et al, 2012) in rats $(n=8)$ maintained ad libitum on standard chow and habituated to ad libitum access to kaolin pellets (aluminum silicate; Research Diets; New Brunswick, NJ) for 4 days. For testing, rats received a $100 \mathrm{nl}$ unilateral lPBN injection of aCSF or exendin- $4(0.05 \mu \mathrm{g})$ in a within-subjects, counterbalanced experimental design immediately before onset of the dark cycle. Food intake, body weight, and kaolin intake were measured $24 \mathrm{~h}$ post injection, accounting for spillage. At least $48 \mathrm{~h}$ elapsed in between drug injection conditions.

Experiment 5: effects of $l P B N$ GLP-1R activation on HFD intake. Rats $(n=11)$ maintained on ad libitum HFD for 5 days received a $100 \mathrm{nl}$ unilateral injection of aCSF or 
exendin-4 $(0.025$ or $0.05 \mu \mathrm{g})$ in a within-subjects, counterbalanced experimental design immediately before the onset of the dark cycle. HFD intake was measured manually at 1 , 3,6 , and $24 \mathrm{~h}$ accounting for spillage. Body weight and water intake were measured $24 \mathrm{~h}$ post injection. At least $48 \mathrm{~h}$ elapsed in between drug injection conditions.

Experiment 6: effects of $1 P B N$ GLP-1R antagonist on standard chow or HFD intake. Rats maintained ad libitum on standard chow $(n=10)$ or on HFD $(n=11)$ for at least 5 days received a $200 \mathrm{nl}$ unilateral injection of aCSF or exendin-(9-39) (20 $\mu \mathrm{g})$ in a within-subjects, counterbalanced experimental design immediately before the onset of the dark cycle. This dose was determined to be subthreshold for an effect on food intake when delivered to the aqueduct (Experiment 2). Standard chow or HFD intake was measured manually at $1,3,6$, and $24 \mathrm{~h}$ accounting for spillage. Body weight and water intake were measured $24 \mathrm{~h}$ post injection. At least $48 \mathrm{~h}$ elapsed in between drug injection conditions.

Experiment 7: effects of $I P B N$ GLP-1R signaling on progressive ratiooperant responding for high-fat chocolate-flavored pellets. Rats $(n=15)$ maintained ad libitum on standard chow were habituated to high-fat (35\%), chocolate-flavored pellets (Bio-Serv; Frenchtown, NJ) in their home cage and trained as previously described (Mietlicki-Baase et al, 2013b) to press a lever for these pellets at an FR5 schedule of reinforcement (five lever presses required to receive one pellet). For all training sessions, the right lever was the active lever and an inactive left lever served as a control for nonconditioned increases or decreases in operant responding.

Rats were given two tests in a within-subjects design using a progressive ratio (PR) schedule of reinforcement, and they received one FR5 session on the day between tests. A $100 \mathrm{nl}$ unilateral $1 \mathrm{PBN}$ injection of $0.025 \mu \mathrm{g}$ of exendin- 4 or aCSF was delivered $4 \mathrm{~h}$ before each PR test session in a within-subjects, counterbalanced experimental design. The 4-h latency between injection and PR test was chosen to be in the middle of the 3-6h time point where ad-libitum food intake is reduced by 1 PBN exendin- 4 administration (Experiments 3 and 5). Animals were returned to their home cage for the $4 \mathrm{~h}$ between injection and test session. During the PR test, the effort required to obtain each pellet increased exponentially throughout the session as previously described (Kanoski et al, 2013; Mietlicki-Baase et al, $2013 \mathrm{~b})$, using the formula $\mathrm{F}(i)=5 \mathrm{e}^{0.2 i}-5$, where $\mathrm{F}(i)$ is the number of lever presses required to obtain the next pellet at $i=$ pellet number. The PR session ended when a $20-\mathrm{min}$ period elapsed without the rat earning a pellet.

Experiment 8: effects of $I P B N$ GLP-1R stimulation and blockade on activity. To determine whether alterations in feeding and food motivation resulting from IPBN GLP-1R activation might be attributable to changes in activity, rats (two groups, $n=11$ for exendin-4, $n=10$ for exendin-(939)) maintained ad libitum on standard chow were habituated to a plexiglass chamber $(74 \mathrm{~cm}$ long, $57.4 \mathrm{~cm}$ wide, $24.7 \mathrm{~cm}$ wall height) for $30 \mathrm{~min}$ each for 3 consecutive days. For testing, rats received a $100 \mathrm{nl}$ unilateral $1 \mathrm{PBN}$ injection of aCSF or exendin-4 $(0.025 \mu \mathrm{g})$, or a $200 \mathrm{nl}$ unilateral IPBN injection of aCSF or exendin-(9-39) $(20 \mu \mathrm{g})$ in a within-subjects counterbalanced experimental design, $4 \mathrm{~h}$ before video recording (timing of injection designed to mimic that of Experiment 7-lPBN exendin-4 effects on PR responding). Rats were then placed in the Plexiglass chamber and recorded with a camera for $30 \mathrm{~min}$. At least $48 \mathrm{~h}$ elapsed between drug injection conditions. Videos were analyzed using ANY-Maze software (Stoelting, Wood Dale, IL) for the total distance traveled and 'time active'. To calculate time spent active, the data were analyzed using two different criteria: 1 and $2 \mathrm{~s}$ (eg, the $1 \mathrm{~s}$ criterion requires the animal to be completely still for $1 \mathrm{~s}$ to be considered not active).

\section{Statistical Analyses}

Data for each experiment were analyzed separately using Statistica (version 7; StatSoft, Tulsa, OK) and expressed as mean $\pm S E M$. For all behavioral experiments, repeated measures ANOVA and post hoc Neumann-Keuls comparisons were made. Alpha levels were set to $\alpha=0.05$ for all analyses.

\section{RESULTS}

Experiment 1: GLP-1-Producing Neurons in the NTS Project Monosynaptically to the IPBN

Analysis of caudal NTS brain sections showed an average of $16.6 \pm 1.5$ GLP-1-producing neurons and 104.8 \pm 9.9 FGexpressing neurons (eg, neurons that project directly from NTS to $1 \mathrm{PBN})$ per $30 \mu \mathrm{m}$ coronal brain section. Overall, $71.3 \%$ of FG-expressing neurons in the NTS projected the FG-injected IPBN ipsilaterally, consistent with a classic anatomical study showing that the majority of NTS projections to PBN are ipsilateral (Norgren, 1978). Quantification of the colocalization of GLP-1 and FG immunoreactivity showed that $23.2 \pm 4.2 \%$ of ipsilateral NTS GLP-1producing neurons and $10.6 \pm 3.0 \%$ of contralateral NTS GLP-1-producing neurons project monosynaptically to the IPBN (Figure 1b). A representative image of a doublelabeled NTS GLP-1-producing neurons following 1PBNinjected fluorogold is shown in Figure 1a.

\section{Experiment 2: Parenchymal dose Selection: Evaluation of Food Intake Effects of GLP-1R Agonist and Antagonist Delivery to the Cerebral Aqueduct}

Cerebral aqueduct delivery of exendin-4 at either dose did not significantly affect cumulative HFD intake at $1 \mathrm{~h}$ $(\mathrm{F}(2,16)=0.62), 3 \mathrm{~h}(\mathrm{~F}(2,16)=0.25), 6 \mathrm{~h}(\mathrm{~F}(2,16)=0.1 .59)$, or $24 \mathrm{~h}(\mathrm{~F}(2,16)=1.17)$ compared with vehicle treatment (Figure 2a). Similarly, exendin-(9-39) delivered to the aqueduct did not significantly affect cumulative HFD intake at $1 \mathrm{~h}(\mathrm{~F}(2,16)=3.54), 3 \mathrm{~h}(\mathrm{~F}(2,16)=0.85), 6 \mathrm{~h}(\mathrm{~F}(2,16)=$ $2.27)$, or $24 \mathrm{~h} .(\mathrm{F}(2,16)=0.31)$ (Figure $2 \mathrm{~b})$. 
Experiment 3: 1PBN GLP-1R Activation Reduces Standard Chow Intake

IPBN GLP-1R activation significantly reduced standard chow intake. There was a significant main effect of IPBN exendin-4 $(0.025$ and $0.05 \mu \mathrm{g})$ on cumulative food intake at
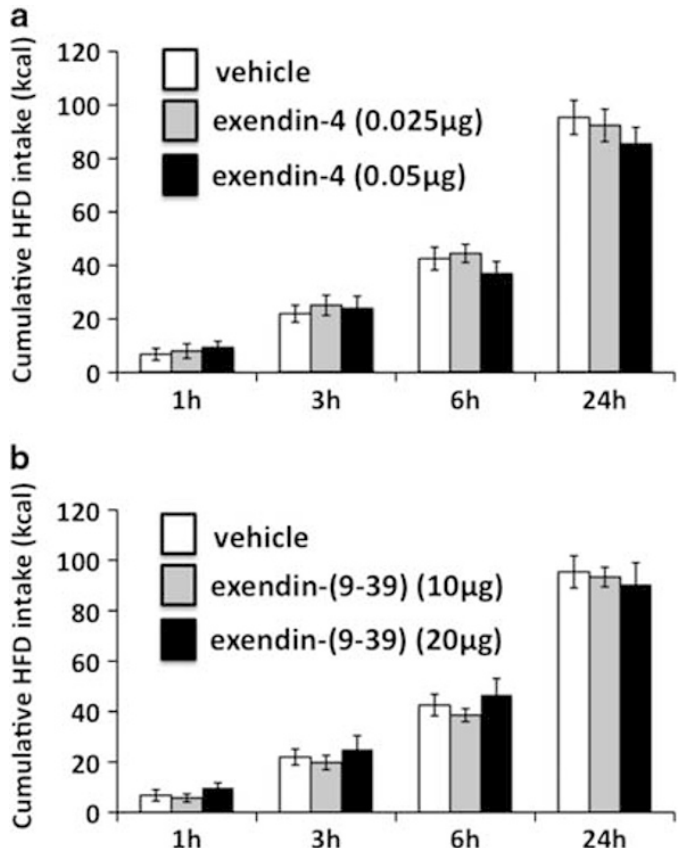

Figure 2 GLP-IR agonist (a) or antagonist (b) injected into the aqueduct just rostral from the level of the PBN had no effect on cumulative food intake (means \pm SEM).
$6 \mathrm{~h} \quad(\mathrm{~F}(2,28)=4.74, \quad p<0.05)$ and $24 \mathrm{~h} \quad(\mathrm{~F}(2,28)=4.51$, $p<0.05)$, and on noncumulative food intake from 3-6h $(\mathrm{F}(2,28)=4.11, p<0.05)$. Post hoc comparisons showed that a significant reduction in cumulative food intake at 6 and $24 \mathrm{~h}$ (Figure $3 \mathrm{a}$ ) and noncumulative food intake (Figure $3 \mathrm{~b}$ ) from 3-6h was observed with each dose of exendin-4 compared with vehicle treatment. There was a nonsignificant trend for IPBN exendin-4 effect on $24 \mathrm{~h}$ change in body weight $(\mathrm{F}(2,28)=3.18, p=0.057$ ) (Figure $3 c$ ) and a significant main effect on $24 \mathrm{~h}$ water intake $(\mathrm{F}(2,24)=6.41$, $p<0.01$ ) (Figure 3d).

\section{Experiment 4: 1PBN GLP-1R Activation does not Cause Pica}

lPBN exendin-4 ( $0.05 \mu \mathrm{g}$ in aCSF) delivery did not affect $24 \mathrm{~h}$ kaolin intake compared with vehicle treatment $(\mathrm{F}(1,8)=1.42)($ Figure $3 \mathrm{e})$.

\section{Experiment 5: 1PBN GLP-1R Activation Reduces HFD Intake}

IPBN GLP-1R activation significantly reduced HFD intake. There was a significant main effect of IPBN exendin-4 (0.025 and $0.05 \mu \mathrm{g})$ on cumulative HFD intake at $6 \mathrm{~h}$ $(\mathrm{F}(2,20)=7.34, \quad p<0.01) \quad$ and $24 \mathrm{~h} \quad(\mathrm{~F}(2,20)=20.89$, $p<0.01)$ along with a significant main effect on noncumulative HFD intake from 3-6h $(\mathrm{F}(2,20)=29.31, p<0.01)$ and $6-24 \mathrm{~h}(\mathrm{~F}(2,20)=18.41, p<0.01)$. Post hoc comparisons showed that each dose of exendin-4 significantly reduced cumulative food intake at 6 and $24 \mathrm{~h}$ (Figure 4a), and noncumulative food intake from 3-6h (Figure 4b), compared with vehicle treatment. There was a significant main

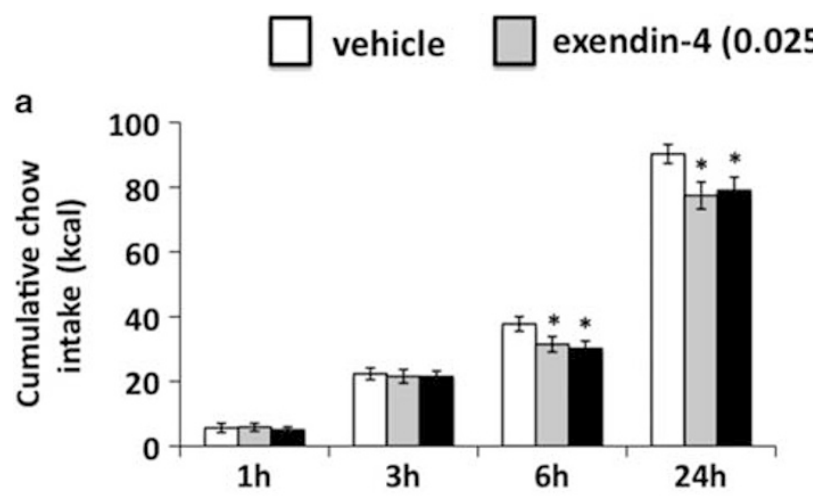

b
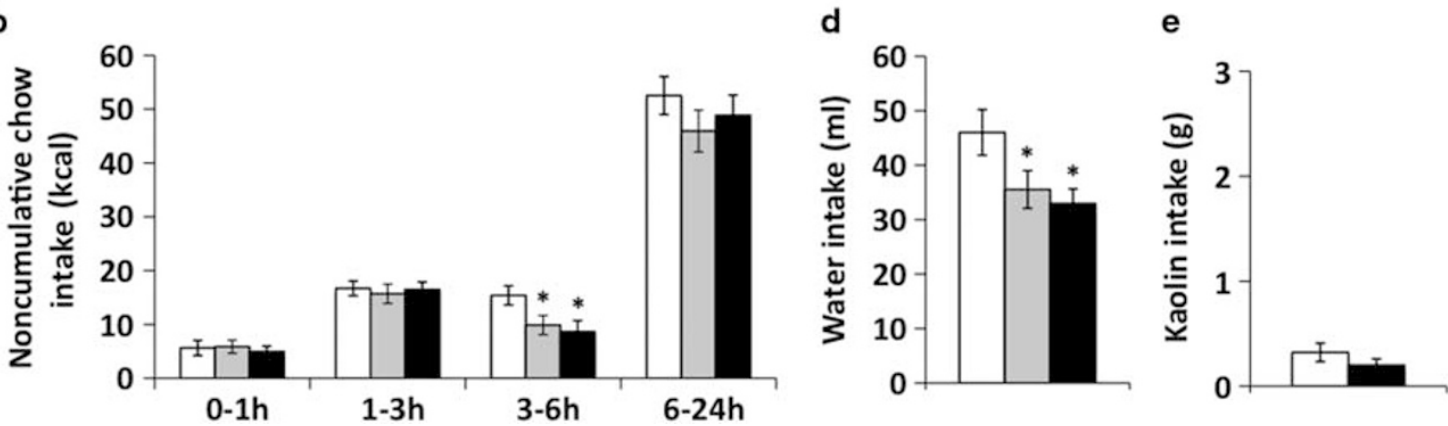

Figure 3 IPBN GLP-IR activation by exendin-4 reduced standard chow and water intake. (a) Cumulative chow intake; (b) noncumulative chow intake; (c) $24 \mathrm{~h}$ change in body weight; (d) $24 \mathrm{~h}$ water intake; and (e) $24 \mathrm{~h}$ kaolin intake (means \pm SEM, * $\mathrm{p}<0.05$ ). 

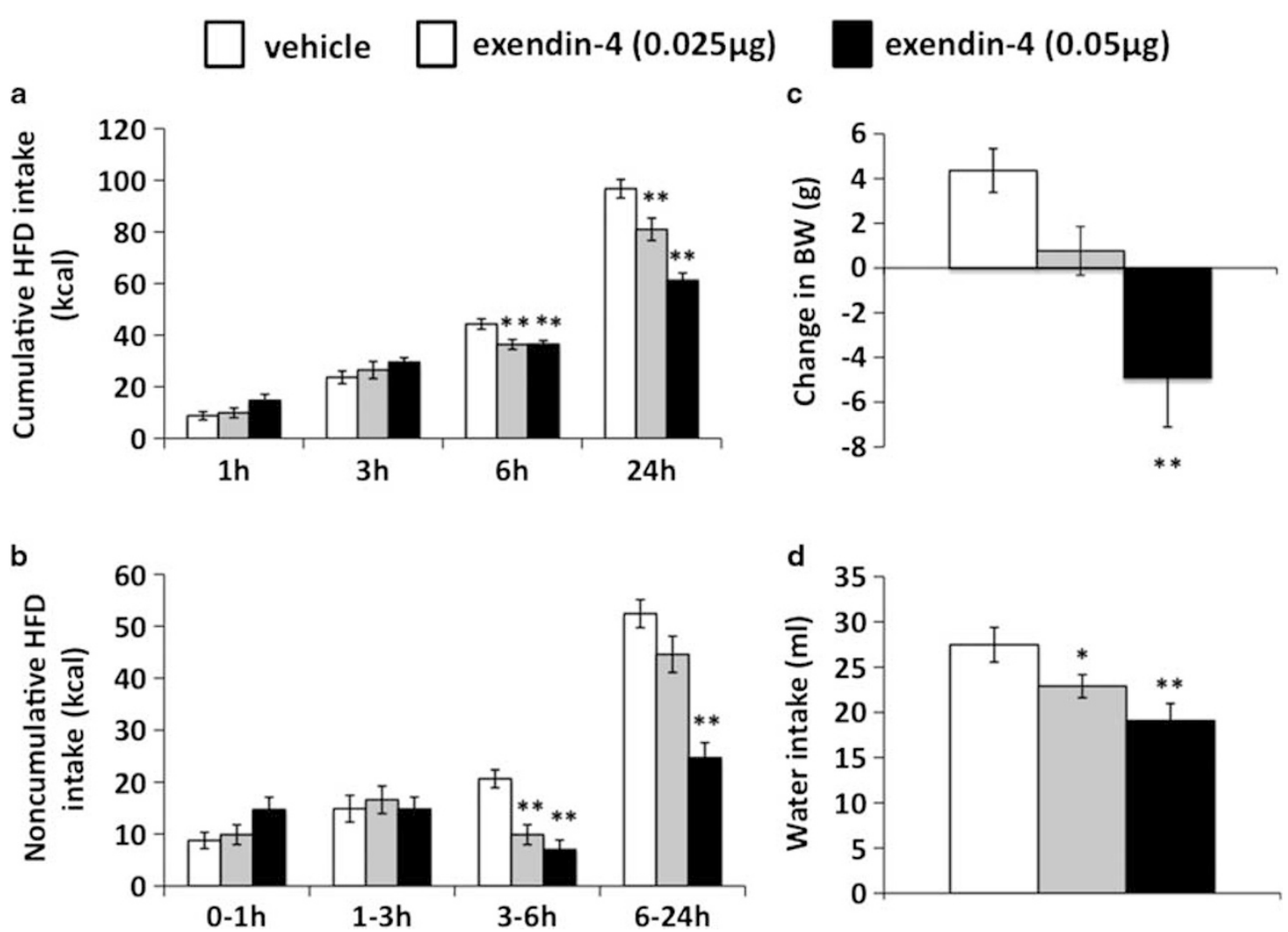

Figure 4 IPBN GLP-IR activation by exendin-4 reduced high-fat diet intake, body weight, and water intake. (a) Cumulative high-fat diet intake; (b) noncumulative high-fat diet intake; (c) $24 \mathrm{~h}$ change in body weight; (d) $24 \mathrm{~h}$ water intake (means $\pm \mathrm{SEM}$, $* \mathrm{p}<0.05$, $* *$ p $<0.0 \mathrm{l}$ ).

effect of $1 \mathrm{PBN}$ exendin-4 (reduction) on $24 \mathrm{~h}$ change in body weight $(\mathrm{F}(2,20)=7.53, p<0.01)$ (Figure $4 \mathrm{c}$ ) and $24 \mathrm{~h}$ water intake $(\mathrm{F}(2,20)=8.52, p<0.01)$ (Figure $4 \mathrm{~d})$.

Experiment 6: 1PBN GLP-1R Antagonism Increases the Intake of Standard Chow and HFD

IPBN GLP-1R antagonism significantly increased cumulative chow and HFD intake at $6 \mathrm{~h}$ post injection $(\mathrm{F}(1,9)=11.27, p<0.01 ; \mathrm{F}(1,10)=10.17, p<0.01$, respectively) (Figure 5a and $\mathrm{c}$ ), and cumulative chow intake at $24 \mathrm{~h}$ post injection $(\mathrm{F}(1,9)=8.85, p<0.05)$. There was no change in $24 \mathrm{~h}$ body weight in animals maintained on chow or $\operatorname{HFD}(\mathrm{F}(1,9)=3.44 ; \mathrm{F}(1,10)=0.37$, respectively) (Figure $5 b$ and $d)$.

Experiment 7: 1PBN GLP-1R Activation Reduces PR Operant Responding for High-Fat, Chocolate-Flavored Pellets

IPBN GLP-1R activation significantly reduced the number of pellets earned $(\mathrm{F}(1,14)=16.08, p<0.01)$ (Figure 6a), as well as the number of active lever presses $(\mathrm{F}(1,14)=15.42$, $p<0.01$ ) (Figure 6b), compared with vehicle treatment in ad libitum fed rats. The number of presses on the inactive control lever was not influenced by lPBN exendin-4 delivery $(\mathrm{F}(1,14)=0.56)$ (Figure 6a).
Experiment 8: 1PBN GLP-1R Stimulation or Blockade has Minimal Effects on Overall Activity

IPBN GLP-1R stimulation did not affect total distance traveled in the activity test $(\mathrm{F}(1,10)=2.18)$ (Figure 7a). IPBN GLP-1R stimulation also did not affect the total time active when the ' $1 \mathrm{~s}$ ' analysis of inactivity was assigned to the data $(\mathrm{F}(1,10)=0.79)$ (Figure $7 \mathrm{~b}$ ), but produced a significant reduction in activity when the ' $2 \mathrm{~s}$ ' analysis of inactivity was assessed $(\mathrm{F}(1,10)=5.75, \quad p=0.038)$ (Figure 7c). 1PBN GLP-1R blockade did not affect total distance traveled in the activity test $(\mathrm{F}(1,10)=0.97)$ (Figure 7d). Likewise, 1PBN GLP-1R blockade had no effect on total time active using the ' $1 \mathrm{~s}$ ' analysis $(\mathrm{F}(1,9)=1.57)$ (Figure $7 \mathrm{e}$ ) or ' $2 \mathrm{~s}$ ' analysis $(\mathrm{F}(1,9)=0.79)$ (Figure $7 \mathrm{f}$ ).

\section{DISCUSSION}

Accumulating evidence supports a role for central GLP-1R signaling in the control of food intake that involves contributions from several anatomically distributed GLP$1 \mathrm{R}$-expressing nuclei including subnuclei of the hypothalamus (eg, paraventricular nucleus (PVH) (McMahon and Wellman, 1998), lateral (LH) and medial (VMH and DMH) nuclei (Schick et al, 2003)), the NTS (Hayes et al, 2009, 2011, and most recently, the reward-associated VTA and NAc (Alhadeff et al, 2012; Dickson et al, 2012; Dossat et al, 2011; Mietlicki-Baase et al, 2013a). Evidence presented here establishes a role for GLP-1R signaling in neurons of the 

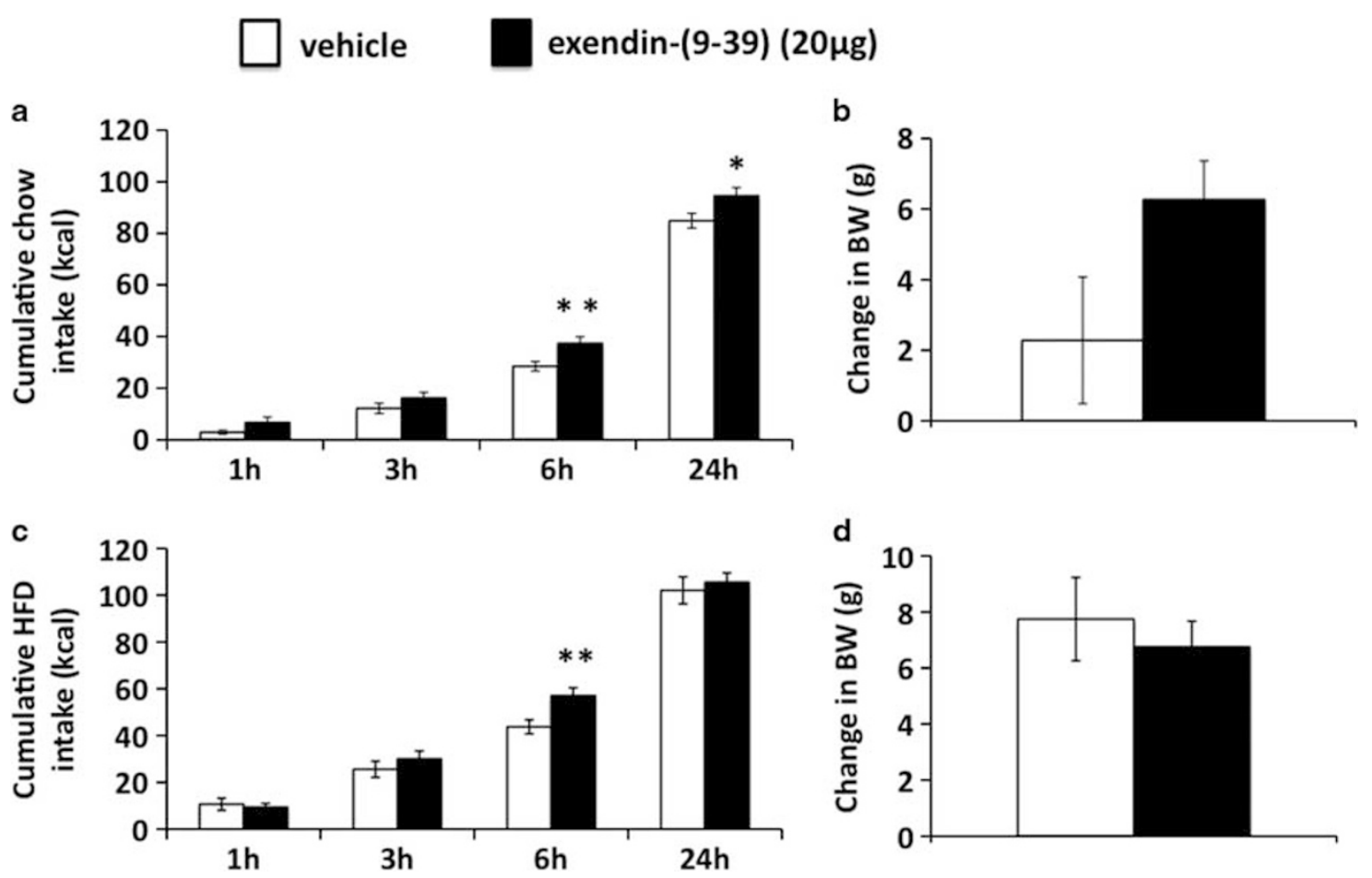

Figure 5 IPBN GLP-IR antagonism by exendin-(9-39) increased standard chow and high-fat diet intake. (a) Cumulative chow intake; (b) 24h change in body weight for animals maintained on chow; (c) cumulative HFD intake; (d) $24 \mathrm{~h}$ change in body weight for animals maintained on HFD (means \pm SEM, $* p<0.05, * * p<0.01$ ).
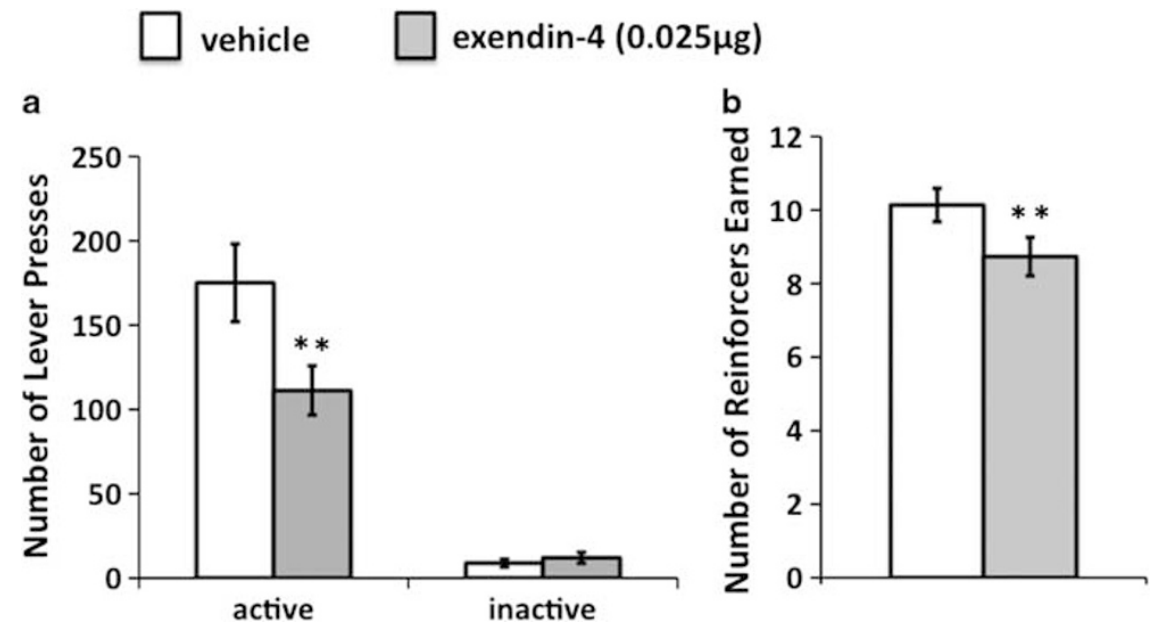

Figure 6 IPBN GLP-IR activation by exendin-4 reduced operant lever responding under a progressive ratio schedule of reinforcement for a high-fat chocolate-flavored reinforcer. (a) Number of active and inactive lever presses; (b) number of reinforcers earned (means \pm SEM, *** $<<0.0 \mathrm{I}$ ).

IPBN. Our results show that GLP-1-expressing neurons of the NTS project directly to the $1 \mathrm{PBN}$, and suggest that these projections are physiologically relevant for the control of food intake as antagonism of GLP-1R in the $1 P B N$ increases both standard chow and HFD intake. When IPBN GLP-1R are activated by parenchymal agonist delivery, food intake and body weight are reduced, as is the motivation to work for palatable food.

Previous research shows dense projections from the caudal NTS to the PBN (Rinaman, 2010), as well as GLP-1R mRNA and GLP-1 immunoreactivity in the PBN
(Merchenthaler et al, 1999; Rinaman, 2010). Those studies, however, left unresolved whether $\mathrm{PBN}$ neurons receive monosynaptic projections from NTS GLP-1-producing neurons to the PBN. Using a strategy similar to Larsen et al (1997) and Alhadeff et al (2012), neuroanatomical tracing combined with IHC for GLP-1 showed that approximately $23 \%$ of ipsilateral and $10 \%$ of contralateral GLP-1-producing NTS neurons project directly to the IPBN. Although postmortem analysis of PBN tissue shows that the $300 \mathrm{nl}$ injection spanned the majority of the PBN and was centered at the IPBN, we cannot completely exclude the 

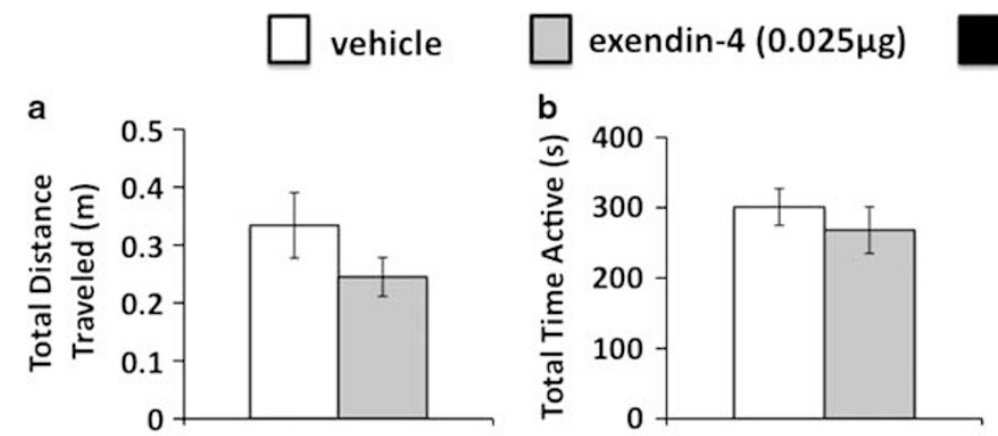

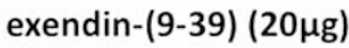
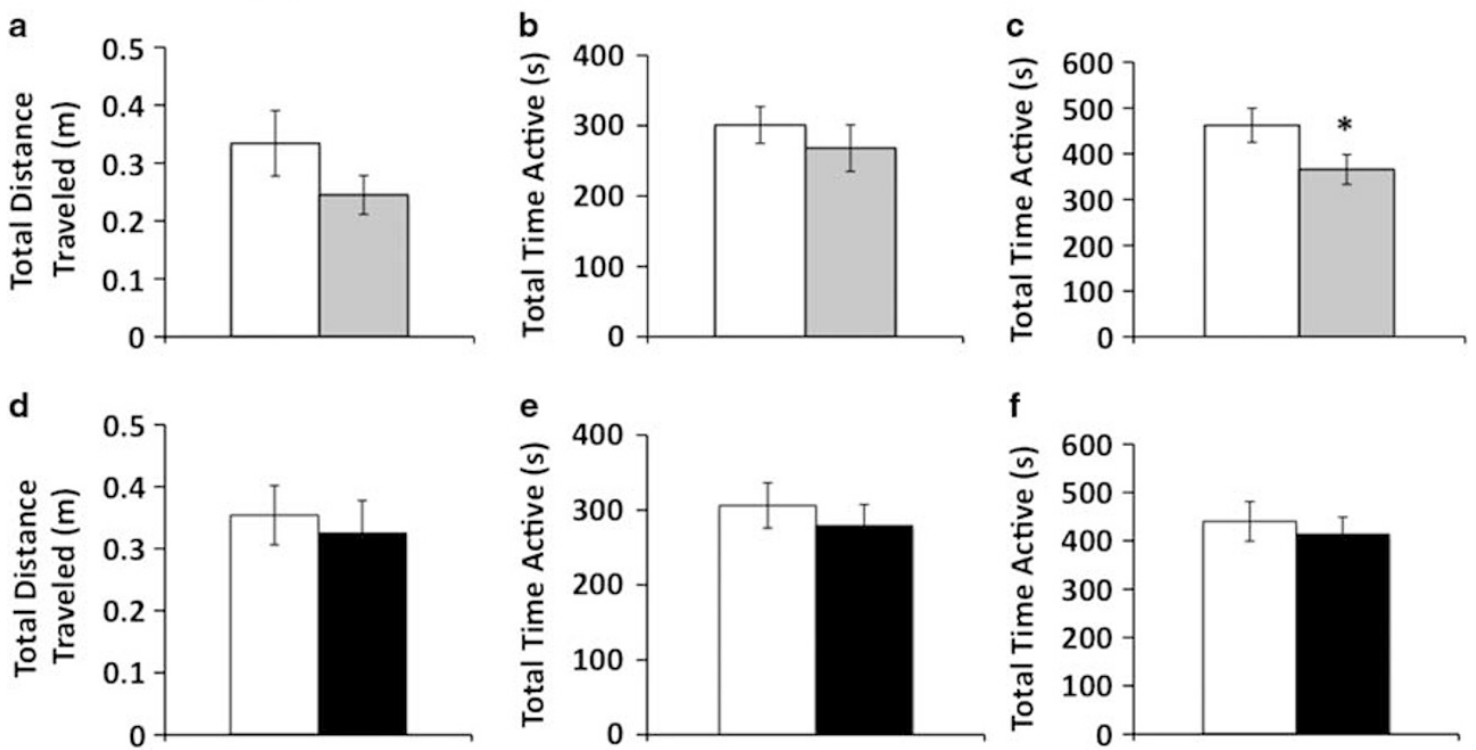

Figure 7 IPBN GLP-IR activation by exendin-4 had minimal effect on activity parameters: (a) total distance traveled; (b) total time active, with animal still for > I s to be considered inactive; (c) total time active, with animal still for $>2$ s to be considered inactive. IPBN GLP-IR blockade by exendin-(9-39) had no effect on activity: (d) total distance traveled; (e) total time active, with animal still for $>$ I $\mathrm{s}$ to be considered inactive; (f) total time active, with animal still for $>2 \mathrm{~s}$ to be considered inactive (means $\pm \mathrm{SEM}, * p<0.05$ ).

possibility that (1) not all of the axon terminals in the PBN took up the Fluorogold tracer or (2) some of the injected FG could have spread outside of the lateral subnucleus of the PBN. Despite these minor methodological limitations, these neuroanatomical tracing data, together with the current pharmacological results showing that IPBN-directed GLP$1 \mathrm{R}$ antagonism increases food intake, provide evidence for an endogenous contribution of IPBN GLP-1R signaling to the control of food intake.

An important topic for further research is to determine which physiological signals activate these NTS-to-PBN GLP-1 neurons. One relevant class of signals to pursue is satiation signals arising from the gut in response to the ingestion of food, such as gastric distension and the release of cholecystokinin (CCK). Gastric distension activates NTS GLP-1-producing neurons (Vrang et al, 2003), and has also been shown to stimulate PBN neural activity through the visceral afferent pathway (Baird et al, 2001; Karimnamazi et al, 2002). In addition, CCK, which is released from the intestine following the intake of fat and/or protein (Ritter, 2004), stimulates NTS GLP-1-producing neurons (Hisadome et al, 2011). Thus, it is possible that GLP-1 is released in the IPBN as a consequence of activation of NTS GLP-1 neurons following post-prandial satiation signaling; this speculation requires direct investigation.

Although GLP-1 is released from enteroendocrine L cells in the intestine in addition to neurons in the NTS, GLP-1 is rapidly degraded by the enzyme dipeptidyl peptidase-IV (DPP-IV) so that its half-life is only 1-2 min (Holst, 2007). However, there are two long-acting, DPP-IV-resistant GLP$1 \mathrm{R}$ agonists that are FDA approved for the treatment of type-2 diabetes mellitus: exendin-4 (Byetta, the GLP-1R agonist used in the current studies) and liraglutide (Victoza). Following peripheral administration, these long- acting GLP-1R agonists can enter the brain (Goke et al, 1995) and activate central GLP-1R to reduce food intake (Kanoski et al, 2011b). Thus, it is possible that peripheral GLP-1R agonists may reach and act in the IPBN to reduce food intake and motivation. This untested idea has clinical implications for the development of therapeutics for the treatment of obesity.

Exendin-4 delivered to the IPBN, at doses subthreshold for effect when delivered ventricularly, significantly reduced cumulative chow (Experiment 3) and HFD (Experiment 5) intake at 6 and $24 \mathrm{~h}$. For both food types, noncumulative effects of exendin-4 were strongest in the 3-6h time bin. GLP-1R antagonist delivery increased food intake with a latency of feeding effect similar to that seen with the agonist, providing a complementary time course for effects. It is interesting to note that several hours elapse between the agonist or antagonist injection and the time that the effects on intake are observed. A cautious explanation for this observation is that 1 PBN GLP-1R activation involves longerterm changes in gene transcription and protein synthesis to elicit its energy balance effects, a notion that has been discussed previously in more detail (Grill and Hayes, 2012; Hayes, 2012; Hayes et al, 2010). It is also likely that IPBN GLP-1R signaling not only results in cellular changes in the IPBN itself, but also engages other brain nuclei to exert effects on feeding and food reward, a process that may take hours to manifest. Elucidating the brain nuclei, projection pathways and neurotransmitter systems that are involved in the mediation of IPBN GLP-1R signaling induced changes in food intake is therefore a topic that warrants further research.

Recent evidence supports the idea that central GLP-1R signaling is involved in motivational aspects of food intake (Alhadeff et al, 2012; Dickson et al, 2012; Dossat et al, 2011; 
Mietlicki-Baase et al, 2013a). Here, we investigated whether IPBN GLP-1R signaling contributes to food reward. An interpretation of the current findings is that IPBN GLP-1R activation reduces food intake, at least in part, by reducing the motivation to work for food. Indeed, IPBN GLP-1R activation significantly reduced active lever presses and the number of food reinforcers obtained on a PR schedule of reinforcement where the effort required to obtain a reinforcer exponentially increased with each successive reinforcer earned. Given the direct anatomical connections between the PBN and other energy balance relevant and reward-related brain nuclei, it is not surprising that $\mathrm{PBN}$ GLP-1R activation contributes to the control of food intake and motivation to work for food. For example, there are monosynaptic connections from the PBN to the VTA (Miller et al, 2011) and the NAc (Brog et al, 1993; Li et al, 2012), brain nuclei of the mesolimbic pathway that are involved in modulating dopamine neurotransmission and food motivation. Indeed, recent evidence suggests that the PBN may provide synaptic information about gustation to dopaminergic neurons in the VTA (Overton et al, 2014). Thus, IPBN GLP-1R-expressing neurons may be engaging these structures to exert effects on the motivation to feed. Future studies should determine the precise anatomical output(s) of IPBN GLP-1R-expressing neurons.

The complementary effects of 1PBN GLP1-R agonist and antagonist delivery on feeding is consistent with an interpretation of a role for endogenous 1PBN GLP-1R signaling in the control of food intake. However, there are a few potential alternate explanations for our findings that IPBN GLP-1R activation reduces food intake and the motivation to feed. Given that systemically administered GLP-1R agonists are associated with nausea in some humans (Buse et al, 2004, 2009) and can produce a conditioned taste avoidance in rodents (Kinzig et al, 2002), we wanted to examine the possibility that IPBN GLP-1R activation may be eliciting malaise which could contribute to the suppression of food intake following direct exendin-4 administration. Thus, pica, an experimental rodent model used to measure nausea/malaise (Andrews and Horn, 2006), was directly examined. Pica involves the consumption of nonnutritive substances (eg, kaolin clay) in response to nausea-inducing agents (Andrews and Horn, 2006) and this model of nausea is especially useful in rodent species that lack the physiology to vomit. The finding that 1 PBN GLP-1R activation by exendin- 4 does not induce pica indicates that the reduction in food intake by IPBN GLP-1R activation is not likely explained by nausea/malaise. This finding is interesting given that there are populations of neurons in the IPBN, especially in the external lateral subregion, that are activated by noxious stimuli (eg, lipopolysaccharide or cisplatin) (De Jonghe and Horn, 2009; Elmquist et al, 1996; Gaykema et al, 2009). However, there is a dissociation between the food intake effects and malaise effects of central GLP-1R signaling in some regions of the brain (Alhadeff et al, 2012; Kanoski et al, 2012; Kinzig et al, 2002), ie, it is established that GLP-1R signaling in certain brain nuclei can cause reduction in food intake without signs of malaise, and vice versa. On the basis of the current data, it appears that the GLP-1 system in the 1PBN is affecting food intake independent of nausea/malaise.
It is also possible that drug-induced effects on activity may underlie reductions in food intake and PR responding. Although, IPBN exendin-4 significantly reduced lever pressing in a PR test, the exendin-4-treated rats pressed the lever over 100 times indicating that they were able to execute and sustain operant responding. Nevertheless, Experiment 8 was included to directly test whether IPBN GLP-1R agonism or antagonism affects activity. We found a small but significant reduction in activity by $\mathrm{lPBN}$ exendin4 in one of the parameters measured in this experiment, presenting a potential confound in interpreting the PR results. Overall, however, data analyzed using several parameters align to suggest that there is no compelling evidence that IPBN GLP-1R activation or blockade affects activity, suggesting that the changes in food intake and motivation to obtain food observed in the current experiments are not likely explained by general changes in activity. Although we favor reduced feeding motivation as an explanation for the reduction in food intake and operant responding by IPBN exendin-4, we acknowledge that GLP$1 \mathrm{R}$ stimulation may reduce several types of motivated behaviors (eg, drug taking, sexual activity, etc.), including the motivation to feed. This is an interesting idea that is not directly addressed in these experiments but should be tested in future studies.

Collectively, results of a range of behavioral/pharmacological studies are consistent and show for the first time that IPBN GLP-1R signaling is physiologically relevant to the control of food intake and motivation to work for palatable food. That NTS GLP-1-producing neurons project monosynaptically to the 1PBN provides an endogenous mechanism by which IPBN GLP-1R signaling may contribute to the control of food intake. These results may have broader implications for the development of future GLP-1-based pharmacological treatments for obesity and overconsumption of energy dense/highly-palatable foods.

\section{FUNDING AND DISCLOSURE}

This work was funded by NIH-DK21397 (HJG), NIHDK096139 (MRH), and NIH- F31NS084633 (ALA). HJG has received funding from Novo Nordisk where he also is on the Advisory Board, and MRH has received funding from the Dairy Research Institute; however, the support from these companies has no relevance to the current manuscript. The authors declare no conflict of interest.

\section{ACKNOWLEDGEMENTS}

We thank Rick Ritacco, Danielle Golub, and Daniel Weng for substantial contributions.

\section{REFERENCES}

Alhadeff AL, Rupprecht LE, Hayes MR (2012). GLP-1 neurons in the nucleus of the solitary tract project directly to the ventral tegmental area and nucleus accumbens to control for food intake. Endocrinology 153: 647-658.

Andrews PL, Horn CC (2006). Signals for nausea and emesis: implications for models of upper gastrointestinal diseases. Auton Neurosci 125: 100-115. 
Astrup A, Rossner S, Van Gaal L, Rissanen A, Niskanen L, Al Hakim $M$ et al (2009). Effects of liraglutide in the treatment of obesity: a randomised, double-blind, placebo-controlled study. Lancet 374: 1606-1616.

Baird JP, Travers JB, Travers SP (2001). Parametric analysis of gastric distension responses in the parabrachial nucleus. Am J Physiol Regul Integr Comp Physiol 281: R1568-R1580.

Blessing WW (1997). The Lower Brainstem and Bodily Homeostasis. Oxford University Press: New York, NY.

Brog JS, Salyapongse A, Deutch AY, Zahm DS (1993). The patterns of afferent innervation of the core and shell in the 'accumbens' part of the rat ventral striatum: immunohistochemical detection of retrogradely transported fluoro-gold. J Comp Neurol 338: 255-278.

Buse JB, Henry RR, Han J, Kim DD, Fineman MS, Baron AD (2004). Effects of exenatide (exendin-4) on glycemic control over 30 weeks in sulfonylurea-treated patients with type 2 diabetes. Diabetes Care 27: 2628-2635.

Buse JB, Rosenstock J, Sesti G, Schmidt WE, Montanya E, Brett JH et al (2009). Liraglutide once a day versus exenatide twice a day for type 2 diabetes: a 26-week randomised, parallel-group, multinational, open-label trial (LEAD-6). Lancet 374: 39-47.

Chaijale NN, Aloyo VJ, Simansky KJ (2013). The stereoisomer $(+)$-naloxone potentiates G-protein coupling and feeding associated with stimulation of mu opioid receptors in the parabrachial nucleus. J Psychopharmacol 27: 302-311.

Cho YK, Li CS, Smith DV (2002). Gustatory projections from the nucleus of the solitary tract to the parabrachial nuclei in the hamster. Chem Senses 27: 81-90.

De Jonghe BC, Horn CC (2009). Chemotherapy agent cisplatin induces 48 -h Fos expression in the brain of a vomiting species, the house musk shrew (Suncus murinus). Am J Physiol Regul Integr Comp Physiol 296: R902-R911.

De Oliveira LB, Kimura EH, Callera JC, De Luca LA Jr, Colombari DS, Menani JV (2011). Baclofen into the lateral parabrachial nucleus induces hypertonic sodium chloride and sucrose intake in rats. Neuroscience 183: 160-170.

Dickson SL, Shirazi RH, Hansson C, Bergquist F, Nissbrandt H, Skibicka KP (2012). The glucagon-like peptide 1 (GLP-1) analogue, exendin-4, decreases the rewarding value of food: a new role for mesolimbic GLP-1 receptors. J Neurosci 32: 4812-4820.

DiPatrizio NV, Simansky KJ (2008). Activating parabrachial cannabinoid CB1 receptors selectively stimulates feeding of palatable foods in rats. J Neurosci 28: 9702-9709.

Dossat AM, Lilly N, Kay K, Williams DL (2011). Glucagonlike peptide 1 receptors in nucleus accumbens affect food intake. J Neurosci 31: 14453-14457.

Elmquist JK, Scammell TE, Jacobson CD, Saper CB (1996). Distribution of Fos-like immunoreactivity in the rat brain following intravenous lipopolysaccharide administration. J Comp Neurol 371: 85-103.

Gaykema RP, Daniels TE, Shapiro NJ, Thacker GC, Park SM, Goehler LE (2009). Immune challenge and satiety-related activation of both distinct and overlapping neuronal populations in the brainstem indicate parallel pathways for viscerosensory signaling. Brain Res 1294: 61-79.

Goke R, Larsen PJ, Mikkelsen JD, Sheikh SP (1995). Distribution of GLP-1 binding sites in the rat brain: evidence that exendin- 4 is a ligand of brain GLP-1 binding sites. Eur J Neurosci 7: 2294-2300.

Grill HJ, Hayes MR (2012). Hindbrain neurons as an essential hub in the neuroanatomically distributed control of energy balance. Cell Metab 16: 296-309.

Hayes MR (2012). Neuronal and intracellular signaling pathways mediating GLP-1 energy balance and glycemic effects. Physiol Behav 106: 413-416.

Hayes MR, Bradley L, Grill HJ (2009). Endogenous hindbrain glucagon-like peptide-1 receptor activation contributes to the control of food intake by mediating gastric satiation signaling. Endocrinology 150: 2654-2659.

Hayes MR, De Jonghe BC, Kanoski SE (2010). Role of the glucagonlike-peptide-1 receptor in the control of energy balance. Physiol Behav 100: 503-510.

Hayes MR, Leichner TM, Zhao S, Lee GS, Chowansky A, Zimmer D et al (2011). Intracellular signals mediating the food intakesuppressive effects of hindbrain glucagon-like peptide-1 receptor activation. Cell Metab 13: 320-330.

Hisadome K, Reimann F, Gribble FM, Trapp S (2011). CCK stimulation of GLP-1 neurons involves alpha1-adrenoceptormediated increase in glutamatergic synaptic inputs. Diabetes 60: 2701-2709.

Holst JJ (2007). The physiology of glucagon-like peptide 1. Physiol Rev 87: 1409-1439.

Kanoski SE, Alhadeff AL, Fortin SM, Gilbert JR, Grill HJ (2013). Leptin signaling in the medial nucleus tractus solitarius reduces food seeking and willingness to work for food. Neuropsychopharmacology 39: 605-613.

Kanoski SE, Fortin SM, Arnold M, Grill HJ, Hayes MR (2011a). Peripheral and central GLP-1 receptor populations mediate the anorectic effects of peripherally administered GLP-1 receptor agonists, liraglutide and exendin-4. Endocrinology 152: 3103-3112.

Kanoski SE, Fortin SM, Arnold M, Grill HJ, Hayes MR (2011b). Peripheral and central GLP-1 receptor populations mediate qthe anorectic effects of peripherally administered GLP-1 receptor agonists, liraglutide and exendin-4. Endocrinology 152: 3103-3112.

Kanoski SE, Rupprecht LE, Fortin SM, De Jonghe BC, Hayes MR (2012). The role of nausea in food intake and body weight suppression by peripheral GLP-1 receptor agonists, exendin-4 and liraglutide. Neuropharmacology 62: 1916-1927.

Karimnamazi H, Travers SP, Travers JB (2002). Oral and gastric input to the parabrachial nucleus of the rat. Brain Res 957: 193-206.

Kinzig KP, D'Alessio DA, Seeley RJ (2002). The diverse roles of specific GLP-1 receptors in the control of food intake and the response to visceral illness. J Neurosci 22: 10470-10476.

Larsen PJ, Tang-Christensen M, Holst JJ, Orskov C (1997). Distribution of glucagon-like peptide-1 and other preproglucagon-derived peptides in the rat hypothalamus and brainstem. Neuroscience 77: 257-270.

Li CS, Chung S, Lu DP, Cho YK (2012). Descending projections from the nucleus accumbens shell suppress activity of tasteresponsive neurons in the hamster parabrachial nuclei. J Neurophysiol 108: 1288-1298.

McMahon LR, Wellman PJ (1998). PVN infusion of GLP-1-(7-36) amide suppresses feeding but does not induce aversion or alter locomotion in rats. Am J Physiol 274(1 Pt 2): R23-R29.

Merchenthaler I, Lane M, Shughrue P (1999). Distribution of pre-proglucagon and glucagon-like peptide-1 receptor messenger RNAs in the rat central nervous system. J Comp Neurol 403: 261-280.

Mietlicki-Baase EG, Ortinski PI, Rupprecht LE, Olivos DR, Alhadeff AL, Pierce RC et al (2013a). The food intakesuppressive effects of glucagon-like peptide-1 receptor signaling in the ventral tegmental area are mediated by AMPA/kainate receptors. Am J Physiol Endocrinol Metab 305: E1367-E1374.

Mietlicki-Baase EG, Rupprecht LE, Olivos DR, Zimmer DJ, Alter MD, Pierce RC et al (2013b). Amylin receptor signaling in the ventral tegmental area is physiologically relevant for the control of food intake. Neuropsychopharmacology 38: 1685-1697.

Miller RL, Stein MK, Loewy AD (2011). Serotonergic inputs to FoxP2 neurons of the pre-locus coeruleus and parabrachial nuclei that project to the ventral tegmental area. Neuroscience 193: $229-240$.

Norgren R (1976). Taste pathways to hypothalamus and amygdala. J Comp Neurol 166: 17-30. 
Norgren R (1978). Projections from the nucleus of the solitary tract in the rat. Neuroscience 3: 207-218.

Overton PG, Vautrelle N, Redgrave P (2014). Sensory regulation of dopaminergic cell activity: phenomenology, circuitry and function. Neuroscience (e-pub ahead of print).

Paxinos G, Watson C (2005). The Rat Brain in Stereotaxic Coordinates. 5th edn Academic Press: San Diego, CA.

Rinaman L (2010). Ascending projections from the caudal visceral nucleus of the solitary tract to brain regions involved in food intake and energy expenditure. Brain Res 1350: 18-34.

Ritter RC (2004). Gastrointestinal mechanisms of satiation for food. Physiol Behav 81: 249-273.

Ritter RC, Slusser PG, Stone S (1981). Glucoreceptors controlling feeding and blood glucose: location in the hindbrain. Science 213: 451-452.

Schick RR, Zimmermann JP, vorm Walde T, Schusdziarra V (2003). Peptides that regulate food intake: glucagon-like peptide 1-(7-36) amide acts at lateral and medial hypothalamic sites to suppress feeding in rats. Am J Physiol Regul Integr Comp Physiol 284: R1427-R1435.

Skibicka KP, Grill HJ (2009). Hypothalamic and hindbrain melanocortin receptors contribute to the feeding, thermogenic, and cardiovascular action of melanocortins. Endocrinology 150: 5351-5361.

Vrang N, Phifer CB, Corkern MM, Berthoud HR (2003). Gastric distension induces c-Fos in medullary GLP-1/2-containing neurons. Am J Physiol Regul Integr Comp Physiol 285: R470-R478.

Wilson JD, Nicklous DM, Aloyo VJ, Simansky KJ (2003). An orexigenic role for mu-opioid receptors in the lateral parabrachial nucleus. Am J Physiol Regul Integr Comp Physiol 285: R1055-R1065.

Wu Q, Boyle MP, Palmiter RD (2009). Loss of GABAergic signaling by AgRP neurons to the parabrachial nucleus leads to starvation. Cell 137: 1225-1234.

Wu Q, Clark MS, Palmiter RD (2012). Deciphering a neuronal circuit that mediates appetite. Nature 483: 594-597.

Zhang C, Kang Y, Lundy RF (2011a). Terminal field specificity of forebrain efferent axons to the pontine parabrachial nucleus and medullary reticular formation. Brain Res 1368: 108-118.

Zhang Y, Kerman IA, Laque A, Nguyen P, Faouzi M, Louis GW et al (2011b). Leptin-receptor-expressing neurons in the dorsomedial hypothalamus and median preoptic area regulate sympathetic brown adipose tissue circuits. J Neurosci 31: 1873-1884. 